\title{
Potential role of gastrointestinal microbiota composition in prostate cancer risk
}

\author{
E Susan Amirian 1,2, Joseph F Petrosino ${ }^{3,4}$, Nadim J Ajami ${ }^{3,4}$, Yanhong Liu ${ }^{1,2}$, Martha P Mims \\ and Michael E Scheurer ${ }^{1,2^{*}}$
}

\begin{abstract}
Background: Among men in the U.S., prostate cancer is the most common cancer and the second leading cause of cancer death. Despite its prevalence, there are few established risk factors for prostate cancer. Some studies have found that intake of certain foods/nutrients may be associated with prostate cancer risk, but few have accounted for how intake and metabolic factors may interact to influence bioavailable nutrient levels and subsequent disease risk.
\end{abstract}

Presentation of the hypothesis: The composition of the gastrointestinal (Gl) microbiome may influence metabolism of dietary compounds and nutrients (e.g., plant phenols, calcium, choline) that may be relevant to prostate cancer risk. We, therefore, propose the hypothesis that Gl microbiota may have a markedly different composition among individuals with higher prostate cancer risk. These individuals could have microbial profiles that are conducive to intestinal inflammation and/or are less favorable for the metabolism and uptake of chemopreventive agents.

Testing the hypothesis: Because very little preliminary data exist on this potential association, a case-control study may provide valuable information on this topic. Such a study could evaluate whether the Gl microbial profile is markedly different between three groups of individuals: healthy men, those with latent prostate cancer, and those with invasive prostate cancer. Any findings could then be validated in a larger study, designed to collect a series of specimens over time.

Implications of the hypothesis: Given the plethora of information emerging from the Human Microbiome Project, this is an opportune time to explore associations between the microbiome and complex human diseases. Identification of profiles that alter the host's risk for disease may clarify inconsistencies in the literature on dietary factors and cancer risk, and could provide valuable targets for novel cancer prevention strategies.

Keywords: Human microbiome, Metagenome, Prostate cancer, Metabolic process

\section{Background}

Prostate cancer is the most common cancer among men in the U.S. [1]. In 2012, approximately 241,740 new diagnoses and 28,170 prostate cancer-related deaths were expected in the U.S. alone (global incidence of 27.9 cases per 100,000) [1,2]. Lifetime risk for prostate cancer is estimated to be $16 \%$, and the median age at diagnosis is 67 years [1].

\footnotetext{
* Correspondence: scheurer@bcm.edu

'Dan L Duncan Cancer Center, Baylor College of Medicine, One Baylor Plaza MS:BCM305, 77030 Houston, TX, USA

${ }^{2}$ Department of Pediatrics, Baylor College of Medicine, One Baylor Plaza MS:BCM305, 77030 Houston, TX, USA

Full list of author information is available at the end of the article
}

Despite its prevalence, there are few established risk factors for prostate cancer [3]. According to twin studies, a proportion of cases (10-40\%) may be explained by genetic factors [3-5]. However, dietary and lifestyle factors may also influence prostate cancer susceptibility $[3,6]$. Intake of red meat [7-10], dairy products [11,12], eggs $[9,13,14]$, green tea $[15,16]$, calcium $[17-20]$, lycopene [21-23], selenium $[6,24]$, and fish oil $[4,25]$ have all been examined in relation to prostate cancer risk with relatively inconsistent results. The inconsistency of these findings may partly be due to the use of food intake measures as surrogates for bioavailable micronutrient levels, resulting in some misclassification of nutrient/metabolite exposures [26,27]. Differing levels of nutrient metabolism 
and absorption from foods between study participants could bias the results of intake studies. Bioavailable micronutrient levels are often determined by complex interactions between intake and metabolism, which are generally not accounted for in such studies.

While many studies have examined self-reported dietary intake of certain foods or biomarkers of specific nutrient levels, few studies have focused on the interactions between how intake and metabolic factors may be working together to influence bioavailable nutrient levels and, potentially, disease risk. The studies that have examined interactions have mostly investigated how genetic variation may affect metabolism or intake (i.e., [28-30]). For example, one recent study investigated the effect of a single-nucleotide polymorphism (rs4988235) in the lactase $(L C T)$ gene on dairy intake, blood analytes, and prostate cancer risk [29]. Although they did not find a significant association with prostate cancer susceptibility, they did report that this variant was correlated with milk intake, with the genotype that confers lower tolerance of lactose-containing foods being associated with lower dairy intake. Another study found that obesity (and its inflammatory sequelae) may modify the impact of arachidonic acid metabolism gene polymorphisms on prostate cancer risk [30]. Nevertheless, genetic factors are only one component of what determines the ability to absorb, convert, and retain dietary nutrients [31-33].

Bioavailable micronutrient levels are not only dependent upon metabolism-related genetic profiles, but are also partly determined by the composition of one's gastrointestinal (GI) microbiota and the metabolic profiles of these GI microorganisms [31,32,34-37]. In fact, the relationship between the GI microbiome and dietary factors is bidirectional- diet influences the composition of the GI microbiome and the GI microbiome affects the digestion and metabolism of dietary factors [37]. Interactions between intake and many species of microbes in the host GI tract have already been well documented $[31,32,38,39]$, and there are several excellent comprehensive review articles currently available on this topic
$[36,37,39]$. Here, we will highlight a few examples of such interactions to show that the GI microbiome and its related metabolic properties can potentially be highly relevant to prostate cancer risk.

Microbial metabolism in the gut can affect dairy product digestion [40], influence the composition of bioactive fatty acids in host adipose tissue [35,41], alter dietary phytochemical digestion/uptake [33], and contribute to the generation of carcinogenic metabolites and inflammation [33,42-45], among many other effects. For example, Lactobacillus acidophilus, is commonly used for probiotic supplementation, as it may aid in lactose digestion [46,47], and Lactobacillus salivarius can help kill Listeria, possibly preventing food-borne illness. Another example involves phenolic compounds from tea, coffee, and other plant-based dietary sources [33]. Some species of GI microbes help digest phenols into biologically active metabolites, which are more readily absorbed by the host $[33,48,49]$. Resveratrol is one such phenol that has been shown to have anti-inflammatory effects by altering eicosanoid production and inhibiting cytokines such as PTGS2, IL6, and TNF $[33,50]$. By providing additional enzymatic action, these and other GI microorganism can have major impacts on the host's digestive process. Some enzymes, such as $\beta$-glucuronidases, that may be of particular relevance to prostate cancer development are involved in conjugation and de-conjugation of sex hormones, such as estrogen [51-53]. In fact, fecal microbial richness and alpha diversity have previously been associated with total urinary estrogen levels [52]. In addition to these examples, a few other illustrations of potentially relevant relationships between xenobiotics and GI microorganisms are provided in Table 1.

A recent review article provided further rationale behind why the GI bacterial community should be viewed as a biodynamic system that interacts with its living environment [38] and may, thus, affect disease risk. This recent article focused on the hypothesis that GI microbes could influence prostate cancer risk based on the presence of isoflavone-metabolizing, equol-producing bacteria. Equol, which has anti-androgenic properties, is

Table 1 Examples of known associations between components of the gastrointestinal microbiome and xenobiotic compounds*

\begin{tabular}{|c|c|c|c|c|}
\hline Xenobiotics & Xenobiotic Function & Metabolizing Bacteria & Effect & Reference \\
\hline Selenium & Antioxidant & Unknown & $\begin{array}{l}\text { Partial sequestration, limiting availability } \\
\text { to host }\end{array}$ & {$[54]$} \\
\hline $\begin{array}{l}\text { 2-Amino-3-methylimidazo } \\
{[4,5-f] \text { quinoline }(\mathrm{IQ})}\end{array}$ & $\begin{array}{l}\text { Carcinogenic heterocyclic } \\
\text { amine, food-borne }\end{array}$ & $\begin{array}{l}\text { Bacteroides, Clostridium, } \\
\text { Escherichia }\end{array}$ & $\begin{array}{l}\text { Degraded into 7-hydroxy-IQ } \\
\text { (direct mutagen) by } \\
\beta \text {-glucuronidase }\end{array}$ & {$[55][56]$} \\
\hline Diadzein & Soy phytoestrogen & Unknown & $\begin{array}{l}\text { Metabolized into equol or non-estrogenic } \\
\text { metabolites }\end{array}$ & {$[57]$} \\
\hline Methylmercuric chloride & Mercuric toxicity & Unknown & Reduction of mercuric tissue content & [58] \\
\hline
\end{tabular}

*Examples identified through PharmacoMicrobiomics: The Drug-Microbiome Portal (http://pharmacomicrobiomics.com/). 
being tested as a potential chemopreventive agent. The idea of Slackia sp. NATTS strain bacteria metabolizing daidzein into equol, which may, subsequently, influence prostate cancer susceptibility, provides yet another example of how the GI microbiome could impact digestion and potentially have downstream systemic effects. With a ratio of about 10 microbes for each eukaryotic cell in the human body $[59,60]$, it is likely that the human microbiome has major physiological and metabolic impacts that we have yet to uncover.

Plotter and Blaser have suggested that human cancers should be considered in the milieu of host-microbiome interactions. They previously described three paradigms relating how the microbiome may be involved in cancer development and pathogenesis. The first involves constituents of the microbiome having inflammatory effects in a lumenal organ. The second paradigm revolves around the metabolic effects of the host's GI microbiome indirectly contributing to distal malignancies via the human estrobolome. The estrobolome is defined as the set of enteric bacterial genes which code for proteins involved in estrogen metabolism. This paradigm may be particularly relevant to our proposed hypothesis due to the reported associations between estrogens and prostate cancer risk [53,61]. The third paradigm is related to the alteration of clinical latency preceding malignancies.

Additionally, there are several specific mechanisms (some of which could fall under one or more of the aforementioned paradigms) through which the GI microbiome could have downstream effects on cancer risk, including competitive inhibition of pathogenic bacteria, production of antibacterial compounds (i.e., bacteriocins) and acids, gene transference between food-borne microbes and members of the GI microbiota, and modulation of the host's immune system $[37,62]$. The exact mechanisms by which the GI microbiome may distally affect cancer risk is likely to be different depending on the cancer site. Nevertheless, the first step to determining how influential the GI microbiome may be in prostate cancer development is to assess whether there are key distinctions in the microbial profiles of men who do and do not develop aggressive disease.

\section{Presentation of the hypothesis}

Our hypothesis is that gastrointestinal microbiota may have a markedly different composition among individuals with higher prostate cancer risk. It is expected that men who are more susceptible to the development of aggressive disease will have similarities in their microbial/ metabolic profiles that diverge from the profiles of healthy men. With regard to the microbial profiles of interest, our hypothesis is not, per se, contingent upon the taxonomic composition of the GI microbiome of low- versus highrisk individuals, but rather the different metabolic and functional profiles represented by the GI microbial community. Given that different taxa of bacteria can have similar metabolic effects, both taxonomic and metabolic profiles should be identified and compared between highand low-risk men. Furthermore, because of the varied effects that intestinal bacteria can have on the host, many of which are still being uncovered, functional studies and research into the specific mechanisms of action will be necessary to explain any microbial or metabolic differences found. Individuals with higher prostate cancer susceptibility may potentially have microbial profiles that are more conducive to intestinal inflammation and/or less favorable for the metabolism and uptake of chemopreventive agents, certain micronutrients, etc.

\section{Testing the hypothesis}

Testing our hypothesis may involve a distinct set of challenges. Although a case-control design seems appropriate, a prospective study would better distinguish between cancer-induced changes in the microbiome, as opposed to changes that may play an etiologic or augmentative role in carcinogenesis (Table 2). Khan et al. posit that there are at least five mechanisms through which the microbiome could be altered by cancer development [63]. Changes to cell surface receptors and ligands may prevent a microbe from selectively binding to certain host cells. The process of carcinogenesis may also involve immunological alterations, which can prevent recognition of pathogenic versus symbiotic bacteria. Further hormonal, anatomical, and enzymatic changes that occur in the host's body during cancer development may produce a host environment that inhibits survival of one microbe over another. Additional concerns involve changes that may occur in the GI microbial profile due to post-diagnostic alterations in diet among cases during therapy.

Another concern regarding the temporality of potential associations between the microbiome and cancer development relates to the "driver-passenger model" that has been proposed for colorectal cancer [64]. Tjalsma et al. posit that colorectal carcinogenesis may be spurred by "driver" bacteria, which can initially induce DNA damage, and are later replaced by "passenger" bacteria that could either delay or enhance tumorogeneis. They suggest that the changing microenvironment surrounding the growth of the tumor may alter selective pressures and, thus, result in the driver bacteria being outcompeted by passenger bacteria (which are defined as commensal organisms that may have tumor promoting or suppressing properties). This driver-passenger model of the involvement of the GI microbiome in colorectal cancer development is probably less applicable to cancers in tissues that have little direct exposure to the microbiome, such as the prostate. Nonetheless, it is possible that physiological changes that occur after the development of 
Table 2 Strengths and limitations of epidemiologic study designs for examining the associations between the gastrointestinal microbiome and prostate cancer risk

\begin{tabular}{|c|c|c|}
\hline Study design & Strengths & Limitations \\
\hline \multirow{3}{*}{$\begin{array}{l}\text { Case-control: } \\
\text { Diagnostically-confirmed latent and invasive } \\
\text { prostate cancer cases compared to each other } \\
\text { and to matched controls }\end{array}$} & - Quick & \multirow{3}{*}{$\begin{array}{l}\text { - Cannot truly establish temporality or } \\
\text { differentiate between cancer-induced and } \\
\text { pre-cancerous changes in the Gl microbiome } \\
\text { - Difficult to obtain appropriate control group }\end{array}$} \\
\hline & \multirow{2}{*}{$\begin{array}{l}\text { - Relatively inexpensive } \\
\text { - No follow-up required }\end{array}$} & \\
\hline & & \\
\hline \multirow{6}{*}{$\begin{array}{l}\text { Prospective Cohort: } \\
\text { Large cohort of older men followed over time } \\
\text { with regular assessments of Gl microbiome } \\
\text { and prostate cancer status }\end{array}$} & \multirow{3}{*}{$\begin{array}{l}\text { - Ability to assess changes from multiple samples as } \\
\text { individuals transition from healthy to cancerous state }\end{array}$} & \multirow{3}{*}{$\begin{array}{l}\text { - Need very large sample size to be able to } \\
\text { obtain enough incident prostate cancer } \\
\text { cases }\end{array}$} \\
\hline & & \\
\hline & & \\
\hline & - Can obtain data on incident cases & - Extremely expensive \\
\hline & $\begin{array}{l}\text { - Can continue to obtain data throughout course of } \\
\text { treatment and progression to assess post-diagnostic } \\
\text { longitudinal and treatment-related changes }\end{array}$ & - Potential biases due to loss to follow \\
\hline & - Can evaluate mortality as an end point & \\
\hline \multirow{4}{*}{$\begin{array}{l}\text { Retrospective Cohort: } \\
\text { Previously collected samples on a large cohort } \\
\text { of men, who were healthy at baseline, } \\
\text { assessed for current prostate cancer status }\end{array}$} & \multirow{3}{*}{$\begin{array}{l}\text { - Likely to have clearer temporality between } \\
\text { assessment of microbial/metabolic profile and } \\
\text { prostate cancer development than in a case-control } \\
\text { study }\end{array}$} & \multirow{3}{*}{$\begin{array}{l}\text { - Requires availability of previously collected } \\
\text { and appropriately preserved samples } \\
\text { (or data) } \\
\text { - Participants must have been cancer-free at } \\
\text { time of sample collection }\end{array}$} \\
\hline & & \\
\hline & & \\
\hline & - Less expensive than prospective cohort study & $\begin{array}{l}\text { - Multiple longitudinal samples are unlikely } \\
\text { to be available }\end{array}$ \\
\hline
\end{tabular}

prostate cancer may, in turn, have an indirect impact on the composition of the GI microbiome. As a result, it is important that the issue of temporality be considered in any study of the possible associations between the GI microbiome and prostate cancer risk.

While knowledge of microbial changes that occur due to cancer development may be useful as potential diagnostic or screening tools, identification of changes in gastrointestinal microbiota that increase one's risk for invasive cancer would provide a key opportunity for cancer prevention. A prospective study design, through expensive and timeconsuming, may afford opportunities to study both these topics, if a large enough cohort of men could be recruited and followed. Exploring the composition of the GI microbiome in relation to prostate cancer risk over time may clarify the findings of previous studies that have inconsistently reported associations between intake of various foods/nutrients and prostate cancer susceptibility by better encompassing the complex set of interactions involved in digestion/metabolism. However, a longitudinal study may present several obstacles related to feasibility, given the incidence of prostate cancer among the general population, the cost of repeated evaluations of microbial profiles, and the need to successfully follow the participants over time while minimizing loss to follow up.

Sample collection could pose another challenge for a longitudinal study on this topic. Many protocols require that stool samples be kept on ice and returned to the lab within 24 hours of collection. A prospective study that requires participants to collect stool, pack it, and return it to the lab within one day may have high loss to follow up, which could be differential between those who go on to develop prostate cancer versus those who do not. This type of selection bias would impact the study findings. Thus, procedures should be streamlined, detailed instructions must be given to participants, and appropriate study incentives should be provided. Ideally, sample collection and processing should follow the protocols set forth and established by The Human Microbiome Project $[65,66]$.

Given the feasibility-related issues that may be associated with a longitudinal study on the GI microbiome and prostate cancer susceptibility, initial studies may realistically need to be retrospective to determine whether this topic is a fruitful area of research. Because little preliminary data exist on this potential association, a case-control study (recruiting incident cases) may provide valuable information, despite its limitations. The GI microbial profiles of healthy men can be compared to those with latent prostate cancer and those with invasive prostate cancer. Alternatively, in a prospective cohort including only diagnostically-confirmed cases, the GI microbiome can feasibly be examined in relation to prostate cancer survival over time among men with aggressive disease to assess its prognostic value.

\section{Implications of the hypothesis}

Investigating the role of the human microbiome in the etiology of complex multifactorial conditions, like cancer, is still a relatively new field. Much research to date has focused on profiling the composition of the microbiome 
across the human body, rather than exploring associations with disease. The recent literature contains several profiles of the bacterial diversity across the human digestive tract [67-70]. However, inter-individual differences in GI microbiome composition are a source of genetic/ metabolic variation that warrant thorough analysis as potential predictors of disease susceptibility.

Even if the hypothesis proposed here is consistently supported by our and other similar studies, establishing causation for this association will likely be relatively difficult. Any differences in the GI microbiome detected between low- and high-risk (or healthy and diseased) men are likely to be neither sufficient nor necessary for the development of malignancy. Furthermore, the association of interest is essentially a network of interactions between the GI microbiome, dietary factors, and the host's other environmental and genetic susceptibility factors. Studying such interactive relationships between interconnected exogenous and endogenous factors has always been challenging, but as the revolutionary new field of molecular pathologic epidemiology continues to evolve, the pathogenic processes behind complex diseases can slowly be uncovered [71,72].

Molecular pathologic epidemiology can be described as the study of the interactive relationships between lifestyle/ dietary factors and molecular tumoral characteristics on the development or progression of a specific molecular subtype of cancer [72]. Because this field will attempt to examine more homogeneous and specific outcomes, while also accounting for the network of biological interactions inevitably at play in the disease process, etiologic relationships that have long eluded us because of the heterogeneity of the case definition (or because of the reductionist approach of simply examining main effects) may begin to be revealed. It follows that simple standards, such as Koch's postulates or Hill's criteria, which have previously been used for establishing causality, are unlikely to be entirely applicable to studies such as the one proposed here (which will be focused on the multiple networks of interactions constituted by the potential relationships between the GI microbiome and prostate cancer) [73]. Therefore, as the field of molecular pathologic epidemiology grows, the criteria by which we assess causality must also evolve to incorporate a more systemic approach.

Nevertheless, given the available information from the Human Microbiome Project [74,75], this is an opportune time to clarify associations between the microbiome and complex diseases [66]. Identification of profiles that alter the host's disease risk may clarify inconsistencies in the literature on dietary factors and cancer risk, and will likely provide novel targets for cancer prevention strategies and personalized medicine [33]. Such strategies may involve personalized probiotic and vitamin/mineral supplementation, fecal transplant [76-78], or the use of antibiotics to achieve a more favorable microbial profile among men whose GI microbiota may support a predisposition to invasive prostate cancer.

\section{Competing interests}

The authors declare no competing interests.

\section{Authors' contributions}

All authors were involved in drafting and critically revising this article. All authors read and approved the final manuscript.

\section{Author details}

${ }^{1}$ Dan L Duncan Cancer Center, Baylor College of Medicine, One Baylor Plaza MS:BCM305, 77030 Houston, TX, USA. ²Department of Pediatrics, Baylor College of Medicine, One Baylor Plaza MS:BCM305, 77030 Houston, TX, USA. ${ }^{3}$ Department of Molcular Virology \& Microbiology, Baylor College of Medicine, One Baylor Plaza MS:BCM305, 77030 Houston, TX, USA. ${ }^{4}$ Alkek Center for Metagenomics and Microbiome Research, Baylor College of Medicine, One Baylor Plaza MS:BCM305, 77030 Houston, TX, USA. ${ }^{5}$ Department of Medicine, Baylor College of Medicine, One Baylor Plaza MS:BCM305, 77030 Houston, TX, USA.

Received: 11 June 2013 Accepted: 12 October 2013

Published: 4 November 2013

\section{References}

1. SEER stat fact sheets: prostate. [http://www.seer.cancer.gov/statfacts/html/ prost.html]

2. Brenner AV, Linet MS, Fine HA, Shapiro WR, Selker RG, Black PM, Inskip PD: History of allergies and autoimmune diseases and risk of brain tumors in adults. Int J Cancer 2002, 99:252-259.

3. Wilson KM, Giovannucci EL, Mucci LA: Lifestyle and dietary factors in the prevention of lethal prostate cancer. Asian J Androl 2012, 14:365-374.

4. Astorg P: Dietary N-6 and N-3 polyunsaturated fatty acids and prostate cancer risk: a review of epidemiological and experimental evidence. Cancer Causes Control 2004, 15:367-386.

5. Page WF, Braun MM, Partin AW, Caporaso N, Walsh P: Heredity and prostate cancer: a study of World War II veteran twins. Prostate 1997, 33:240-245.

6. Sonn GA, Aronson W, Litwin MS: Impact of diet on prostate cancer: a review. Prostate Cancer Prostatic Dis 2005, 8:304-310.

7. Punnen S, Hardin J, Cheng I, Klein EA, Witte JS: Impact of meat consumption, preparation, and mutagens on aggressive prostate cancer. PLoS One 2011, 6:e27711

8. Major JM, Cross AJ, Watters JL, Hollenbeck AR, Graubard BI, Sinha R: Patterns of meat intake and risk of prostate cancer among African-Americans in a large prospective study. Cancer Causes Control 2011 22:1691-1698

9. Richman EL, Kenfield SA, Stampfer MJ, Giovannucci EL, Chan JM: Egg, red meat, and poultry intake and risk of lethal prostate cancer in the prostate-specific antigen-era: incidence and survival. Cancer Prev Res (Phila) 2011, 4:2110-2121.

10. Alexander DD, Mink PJ, Cushing CA, Sceurman B: A review and metaanalysis of prospective studies of red and processed meat intake and prostate cancer. Nutr J 2010, 9:50.

11. Newmark HL, Heaney RP: Dairy products and prostate cancer risk. Nut Cancer 2010, 62:297-299.

12. Lampe JW: Dairy products and cancer. J Am Coll Nutr 2011, 30:464S-470S

13. Richman EL, Kenfield SA, Stampfer MJ, Giovannucci EL, Zeisel SH, Willett WC, Chan JM: Choline intake and risk of lethal prostate cancer: incidence and survival. Am J Clin Nutr 2012, 96:855-863.

14. Xie $\mathrm{B}, \mathrm{He} \mathrm{H}$ : No association between egg intake and prostate cancer risk: a meta-analysis. Asian Pac J Cancer Prev 2012, 13:4677-4681.

15. Montague JA, Butler LM, Wu AH, Genkinger JM, Koh WP, Wong AS, Wang R, Yuan JM, Yu MC: Green and black tea intake in relation to prostate cancer risk among Singapore Chinese. Cancer Causes Control 2012, 23:1635-1641.

16. Ozten-Kandas N, Bosland MC: Chemoprevention of prostate cancer: natural compounds, antiandrogens, and antioxidants - in vivo evidence. J Carcinog 2011, 10:27. 
17. Chan JM, Giovannucci EL: Dairy products, calcium, and vitamin D and risk of prostate cancer. Epidemiol Rev 2001, 23:87-92.

18. Gao X, LaValley MP, Tucker KL: Prospective studies of dairy product and calcium intakes and prostate cancer risk: a meta-analysis. $J$ Natl Cancer Inst 2005, 97:1768-1777.

19. Schwartz $\mathrm{GG}$, Skinner HG: A prospective study of total and ionized serum calcium and time to fatal prostate cancer. Cancer Epidemiol Biomarkers Prev 2012, 21:1768-1773.

20. Chan JM, Stampfer MJ, Ma J, Gann PH, Gaziano JM, Giovannucci EL: Dairy products, calcium, and prostate cancer risk in the Physicians' health study. Am J Clin Nutr 2001, 74:549-554.

21. Key TJ, Appleby PN, Allen NE, Travis RC, Roddam AW, Jenab M, Egevad L, Tjonneland A, Johnsen NF, Overvad K, et al: Plasma carotenoids, retinol, and tocopherols and the risk of prostate cancer in the European prospective investigation into cancer and nutrition study. Am J Clin Nutr 2007, 86:672-681.

22. Wu K, Erdman JW Jr, Schwartz SJ, Platz EA, Leitzmann M, Clinton SK DeGroff V, Willett WC, Giovannucci E: Plasma and dietary carotenoids, and the risk of prostate cancer: a nested case-control study. Cancer Epidemiol Biomarkers Prev 2004, 13:260-269.

23. Teodoro AJ, Oliveira FL, Martins NB, Maia GA, Martucci RB, Borojevic R: Effect of lycopene on cell viability and cell cycle progression in human cancer cell lines. Cancer Cell Int 2012, 12:36.

24. Hurst R, Hooper L, Norat T, Lau R, Aune D, Greenwood DC, Vieira R, Collings R, Harvey $\sqcup$, Sterne JA, et al: Selenium and prostate cancer: systematic review and meta-analysis. Am J Clin Nutr 2012, 96:111-122.

25. Sala-Vila A, Calder PC: Update on the relationship of fish intake with prostate, breast, and colorectal cancers. Crit Rev Food Sci Nutr 2011, 51:855-871.

26. Dennis LK, Snetselaar LG, Smith BJ, Stewart RE, Robbins ME: Problems with the assessment of dietary fat in prostate cancer studies. Am J Epidemiol 2004, 160:436-444.

27. Wei MY, Giovannucci EL: Lycopene, tomato products, and prostate cancer incidence: a review and reassessment in the PSA screening Era. J Oncol 2012, 2012:271063

28. Joshi AD, Corral R, Catsburg C, Lewinger JP, Koo J, John EM, Ingles SA, Stern MC: Red meat and poultry, cooking practices, genetic susceptibility and risk of prostate cancer: results from a multiethnic case-control study. Carcinogenesis 2012, 33:2108-2118.

29. Travis RC, Appleby PN, Siddiq A, Allen NE, Kaaks R, Canzian F, Feller S, Tjonneland A, Fons Johnsen N, Overvad K, et al: Genetic variation in the lactase gene, dairy product intake and risk for prostate cancer in the European prospective investigation into cancer and nutrition. Int $\mathrm{J}$ Cancer 2012, 132:1901-1910

30. Amirian ES, Ittmann MM, Scheurer ME: Associations between arachidonic acid metabolism gene polymorphisms and prostate cancer risk. Prostate 2011, 71:1382-1389.

31. Tilg H: Obesity, metabolic syndrome, and microbiota: multiple interactions. J Clin Gastroenterol 2010, 44(Suppl 1):S16-S18.

32. Tremaroli $V$, Backhed F: Functional interactions between the gut microbiota and host metabolism. Nature 2012, 489:242-249.

33. Macdonald RS, Wagner K: Influence of dietary phytochemicals and microbiota on colon cancer risk. J Agric Food Chem 2012. [Epub ahead of print] PMID: 22632581

34. Musso G, Gambino R, Cassader M: Interactions between gut microbiota and host metabolism predisposing to obesity and diabetes. Annu Rev Med 2011, 62:361-380.

35. Musso G, Gambino R, Cassader M: Obesity, diabetes, and gut microbiota: the hygiene hypothesis expanded? Diabetes Care 2010, 33:2277-2284.

36. Haiser HJ, Turnbaugh PJ: Developing a metagenomic view of xenobiotic metabolism. Pharmacol Res: J Italian Pharmacol Soc 2013, 69:21-31.

37. Dutton RJ, Turnbaugh PJ: Taking a metagenomic view of human nutrition. Curr Opin Clin Nutr 2012, 15:448-454.

38. Akaza H: Prostate cancer chemoprevention by soy isoflavones: role of intestinal bacteria as the "second human genome". Cancer Sci 2012, 103:969-975.

39. Saad R, Rizkallah MR, Aziz RK: Gut pharmacomicrobiomics: the tip of an iceberg of complex interactions between drugs and gut-associated microbes. Gut Pathogens 2012, 4:16.

40. Masood MI, Qadir MI, Shirazi JH, Khan IU: Beneficial effects of lactic acid bacteria on human beings. Crit Rev Microbiol 2011, 37:91-98.
41. Backhed F, Ding H, Wang T, Hooper LV, Koh GY, Nagy A, Semenkovich CF, Gordon J: The gut microbiota as an environmental factor that regulates fat storage. Proc Natl Acad Sci U S A 2004, 101:15718-15723.

42. Russell SL, Finlay BB: The impact of gut microbes in allergic diseases. Curr Opin Gastroenterol 2012, 28:563-569.

43. Arthur JC, Perez-Chanona E, Muhlbauer M, Tomkovich S, Uronis JM, Fan TJ, Campbell BJ, Abujamel T, Dogan B, Rogers AB, et al: Intestinal inflammation targets cancer-inducing activity of the microbiota. Science 2012, 338:120-123.

44. Graessler J, Qin Y, Zhong H, Zhang J, Licinio J, Wong ML, Xu A, Chavakis T, Bornstein $A B$, Ehrhart-Bornstein $M$, et al: Metagenomic sequencing of the human gut microbiome before and after bariatric surgery in obese patients with type 2 diabetes: correlation with inflammatory and metabolic parameters. Pharmacogenomics J 2012. doi: 10.1038/tpj.2012.43. [Epub ahead of print] PMID: 23032991.

45. lebba V, Nicoletti M, Schippa S: Gut microbiota and the immune system: an intimate partnership in health and disease. Int J Immunopathol Pharmacol 2012, 25:823-833.

46. Sanders ME, Klaenhammer TR: Invited review: the scientific basis of lactobacillus acidophilus NCFM functionality as a probiotic. J Dairy Sci 2001, 84:319-331.

47. Montes RG, Bayless TM, Saavedra JM, Perman JA: Effect of milks inoculated with lactobacillus acidophilus or a yogurt starter culture in lactosemaldigesting children. J Dairy Sci 1995, 78:1657-1664.

48. Sekirov I, Russell SL, Antunes LC, Finlay BB: Gut microbiota in health and disease. Physiol Rev 2010, 90:859-904

49. Russell W, Duthie G: Plant secondary metabolites and gut health: the case for Phenolic acids. Proc Nutr Soc 2011, 70:389-396.

50. Namasivayam N: Chemoprevention in experimental animals. Ann N Y Acad Sci 2011, 1215:60-71.

51. Plottel CS, Blaser MJ: Microbiome and malignancy. Cell host \& microbe 2011, 10:324-335.

52. Flores R, Shi J, Fuhrman B, Xu X, Veenstra TD, Gail MH, Gajer P, Ravel J, Goedert JJ: Fecal microbial determinants of fecal and systemic estrogens and estrogen metabolites: a cross-sectional study. J Trans/ Med 2012, 10:253.

53. Cavalieri E, Rogan E: The molecular etiology and prevention of estrogeninitiated cancers. Mol Aspects Med 2013. doi: 10.1016/j.mam.2013.08.002 [Epub ahead of print] PMID: 23994691.

54. Kasaikina MV, Kravtsova MA, Lee BC, Seravalli J, Peterson DA, Walter J, Legge R, Benson AK, Hatfield DL, Gladyshev VN: Dietary selenium affects host selenoproteome expression by influencing the gut microbiota. FASEB J: Publ Fed Am Soc Exp Biol 2011, 25:2492-2499.

55. Humblot C, Combourieu B, Vaisanen ML, Furet JP, Delort AM, Rabot S: $1 \mathrm{H}$ Nuclear magnetic resonance spectroscopy-based studies of the metabolism of food-borne carcinogen 2-amino-3-methylimidazo [4,5-f]quinoline by human intestinal microbiota. App/ Environ Microb 2005, 71:5116-5123

56. Humblot C, Murkovic M, Rigottier-Gois L, Bensaada M, Bouclet A, Andrieux C, Anba J, Rabot S: Beta-glucuronidase in human intestinal microbiota is necessary for the colonic genotoxicity of the food-borne carcinogen 2-amino-3-methylimidazo[4,5-f]quinoline in rats. Carcinogenesis 2007 28:2419-2425.

57. Rafii F, Jackson LD, Ross I, Heinze TM, Lewis SM, Aidoo A, Lyn-Cook L, Manjanatha M: Metabolism of daidzein by fecal bacteria in rats. Comparat Med 2007, 57:282-286.

58. Rowland IR, Davies MJ, Evans JG: Tissue content of mercury in rats given methylmercuric chloride orally: influence of intestinal flora. Arch Environ health 1980, 35:155-160.

59. Li K, Bihan M, Yooseph S, Methe BA: Analyses of the microbial diversity across the human microbiome. PLOS One 2012, 7:e32118.

60. Goodman AL, Gordon Jl: Our unindicted coconspirators: human metabolism from a microbial perspective. Cell Metab 2010, 12:111-116.

61. Carruba G: Estrogen and prostate cancer: an eclipsed truth in an androgen-dominated scenario. J Cell Biochem 2007, 102:899-911.

62. Commane D, Hughes $R$, Shortt $C$, Rowland I: The potential mechanisms involved in the anti-carcinogenic action of probiotics. Mutat Res 2005, 591:276-289.

63. Khan AA, Shrivastava A, Khurshid M: Normal to cancer microbiome transformation and its implication in cancer diagnosis. Biochim Biophys Acta 1826, 2012:331-337. 
64. Tjalsma H, Boleij A, Marchesi JR, Dutilh BE: A bacterial driver-passenger model for colorectal cancer: beyond the usual suspects. Nat Rev Microbiol 2012, 10:575-582.

65. NIH human microbiome project sampling, sequencing, and analysis protocols. [http://www.hmpdacc.org/tools_protocols/tools_protocols.php]

66. Dave M, Higgins PD, Middha S, Rioux KP: The human gut microbiome: current knowledge, challenges, and future directions. Trans/ Res: J Lab Clin Med 2012, 160:246-257.

67. Segata N, Haake SK, Mannon P, Lemon KP, Waldron L, Gevers D, Huttenhower C, Izard J: Composition of the adult digestive tract bacterial microbiome based on seven mouth surfaces, tonsils, throat and stool samples. Genome Biol 2012, 13:R42.

68. Stearns JC, Lynch MD, Senadheera DB, Tenenbaum HC, Goldberg MB, Cvitkovitch DG, Croitoru K, Moreno-Hagelsieb G, Neufeld JD: Bacterial biogeography of the human digestive tract. Sci Rep 2011, 1:170.

69. Huse SM, Ye Y, Zhou Y, Fodor AA: A core human microbiome as viewed through 16S rRNA sequence clusters. PLoS One 2012, 7:e34242.

70. Antonopoulos DA, Huse SM, Morrison HG, Schmidt TM, Sogin ML, Young VB: Reproducible community dynamics of the gastrointestinal microbiota following antibiotic perturbation. Infect Immun 2009, 77:2367-2375.

71. Ogino S, Stampfer M: Lifestyle factors and microsatellite instability in colorectal cancer: the evolving field of molecular pathological epidemiology. J Natl Cancer Inst 2010, 102:365-367.

72. Ogino S, Chan AT, Fuchs CS, Giovannucci E: Molecular pathological epidemiology of colorectal neoplasia: an emerging transdisciplinary and interdisciplinary field. Gut 2011, 60:397-411.

73. Plowright RK, Sokolow SH, Gorman ME, Daszak P, Foley JE: Causal inference in disease ecology: investigating ecological drivers of disease emergence. Front Ecol Environ 2008, 6:420-429.

74. Morgan XC, Segata N, Huttenhower C: Biodiversity and functional genomics in the human microbiome. Trends Genet 2012, 29:51-58.

75. Conlan S, Kong HH, Segre JA: Species-level analysis of DNA sequence data from the NIH human microbiome project. PLoS One 2012, 7:e47075.

76. Vindigni SM, Broussard EK, Surawicz CM: Alteration of the intestinal microbiome: fecal microbiota transplant and probiotics for clostridium difficile and beyond. Expert Rev Gastroenterol Hepatol 2013, 7:615-628.

77. Aroniadis OC, Brandt $\mathrm{L}$ : Fecal microbiota transplantation: past, present and future. Curr Opin Gastroenterol 2013, 29:79-84

78. Paasche S: Fecal microbiota transplantation: an innovative approach to treating clostridium difficile disease. JAAPA: J Am Acad Physic Assistants 2013, 26:46-49.

doi:10.1186/1750-9378-8-42

Cite this article as: Amirian et al:: Potential role of gastrointestinal microbiota composition in prostate cancer risk. Infectious Agents and Cancer 2013 8:42

\section{Submit your next manuscript to BioMed Central and take full advantage of:}

- Convenient online submission

- Thorough peer review

- No space constraints or color figure charges

- Immediate publication on acceptance

- Inclusion in PubMed, CAS, Scopus and Google Scholar

- Research which is freely available for redistribution 